\title{
Vision outcomes in patients with paraclinoid aneurysms treated with clipping, coiling, or flow diversion: a systematic review and meta-analysis
}

\author{
Michael A. Silva, BA, Alfred P. See, MD, Hormuzdiyar H. Dasenbrock, MD, Nirav J. Patel, MD, and \\ Mohammad A. Aziz-Sultan, MD \\ Department of Neurosurgery, Brigham and Women's Hospital, Harvard Medical School, Boston, Massachusetts
}

\begin{abstract}
OBJECTIVE Patients with paraclinoid aneurysms commonly present with visual impairment. They have traditionally been treated with clipping or coiling, but flow diversion (FD) has recently been introduced as an alternative treatment modality. Although there is still initial aneurysm thrombosis, FD is hypothesized to reduce mass effect, which may decompress the optic nerve when treating patients with visually symptomatic paraclinoid aneurysms. The authors performed a meta-analysis to compare vision outcomes following clipping, coiling, or FD of paraclinoid aneurysms in patients who presented with visual impairment.
\end{abstract}

METHODS A systematic literature review was performed using the PubMed and Web of Science databases. Studies published in English between 1980 and 2016 were included if they reported preoperative and postoperative visual function in at least 5 patients with visually symptomatic paraclinoid aneurysms (cavernous segment through ophthalmic segment) treated with clipping, coiling, or FD. Neuroophthalmological assessment was used when reported, but subjective patient reports or objective visual examination findings were also acceptable.

RESULTS Thirty-nine studies that included a total of 2458 patients ( 520 of whom presented with visual symptoms) met the inclusion criteria, including 307 visually symptomatic cases treated with clipping (mean follow-up 26 months), 149 treated with coiling (mean follow-up 17 months), and 64 treated with FD (mean follow-up 11 months). Postoperative vision in these patients was classified as improved, unchanged, or worsened compared with preoperative vision. A pooled analysis showed preoperative visual symptoms in $38 \%(95 \% \mathrm{Cl} 28 \%-50 \%)$ of patients with paraclinoid aneurysms. The authors found that vision improved in 58\% (95\% Cl 48\%-68\%) of patients after clipping, $49 \%$ (95\% Cl 38\%-59\%) after coiling, and $71 \%$ (95\% Cl 55\%-84\%) after FD. Vision worsened in $11 \%(95 \% \mathrm{Cl} 7 \%-17 \%)$ of patients after clipping, $9 \%$ (95\% Cl 2\%-18\%) after coiling, and 5\% (95\% Cl 0\%-20\%) after FD. New visual deficits were found in patients with intact baseline vision at a rate of $1 \%(95 \% \mathrm{Cl} 0 \%-3 \%)$ for clipping, $0 \%(95 \% \mathrm{Cl} \% \%-2 \%)$ for coiling, and $0 \%(95 \% \mathrm{Cl} 0 \%-2 \%)$ for FD.

CONCLUSIONS To the authors' knowledge, this is the first meta-analysis to assess vision outcomes after treatment for paraclinoid aneurysms. The authors found that $38 \%$ of patients with these aneurysms presented with visual impairment. These data also demonstrated a high rate of visual improvement after FD without a significant difference in the rate of worsened vision or iatrogenic visual impairment compared with clipping and coiling. These findings suggest that FD is an effective option for treatment of visually symptomatic paraclinoid aneurysms.

https://thejns.org/doi/abs/10.3171/2017.3.FOCUS1718

KEY WORDS endovascular coiling; flow diversion; microsurgical clipping; paraclinoid aneurysm; Pipeline embolization device

$\mathrm{P}$ ATIENTS with aneurysms of the paraclinoid segment of the internal carotid artery (ICA) commonly present with visual impairment. Paraclinoid aneurysms can be broadly described to affect the ICA between the cavernous segment and the origin of the posterior communicating artery. Some of the most common aneurysms of this segment include ophthalmic artery aneurysms and superior hypophyseal aneurysms. Aneurysms of the cavernous segment of the ICA and other less common variants are also observed.

The proximity of these aneurysms to the optic nerve and the ophthalmic artery can impair patient vision. Be-

ABBREVIATIONS FD = flow diversion; ICA = internal carotid artery; MeSH = Medical Subject Headings; PED = Pipeline embolization device; tiab = title/abstract. SUBMITTED January 22, 2017. ACCEPTED March 16, 2017. INCLUDE WHEN CITING DOI: 10.3171/2017.3.FOCUS1718. 
tween $16 \%$ and $40 \%$ of patients with paraclinoid aneurysms present with visual deficits..$^{11,31,46}$ The mechanism of visual impairment is not well understood, but may result from direct mass effect of the aneurysm sac compressing the optic nerve, inflammation, or retinal artery thrombosis. ${ }^{1,18,24,28,46,49}$ In addition to presenting with visual symptoms, patients with intact baseline vision can develop iatrogenic visual deficits following treatment by many of these same mechanisms.

Paraclinoid aneurysms have traditionally been treated with either clipping or coiling, but few studies have comprehensively compared vision outcomes between these treatment modalities. Flow diversion (FD) represents an alternative modality for treatment of intracranial aneurysms. An endoluminal stent is deployed into the parent vessel across the aneurysm to reconstruct the vessel wall and to exclude blood from the aneurysm sac. ${ }^{19,27}$ Initially intended to treat large, wide-necked aneurysms, flowdiverting stents such as the Pipeline embolization device (PED) have demonstrated improved aneurysm occlusion, lower rates of recanalization, and greater reduction of mass effect compared with coiling. ${ }^{19}$ FD is now being used more broadly for aneurysms that are not large and are not broad necked, including for paraclinoid aneurysms. ${ }^{7,46}$ The recent expansion in the use of FD for paraclinoid aneurysms has yielded sufficient data for it to be compared with clipping and coiling.

Many studies have compared aneurysm occlusion rates and recanalization rates among these treatment modalities, but few have looked at more nuanced quality-of-life outcomes such as vision. We performed a systematic review and meta-analysis to compare vision outcomes of clipping, coiling, or FD of paraclinoid aneurysms in patients presenting with visual impairment. We also sought to assess the rate at which patients with paraclinoid aneurysms present with visual impairment and the rate at which patients with intact preoperative vision develop iatrogenic visual impairment after treatment.

\section{Methods \\ Literature Search}

The PubMed and Web of Science databases were searched for literature published in English between January 1980 and April 2016. See Appendix for search terms, with Medical Subject Headings (MeSH) and title/abstract (tiab) as qualifiers. Studies were considered for inclusion if they reported on either unruptured paraclinoid aneurysms or subarachnoid hemorrhage from a paraclinoid aneurysm causing visual symptoms and treated with microsurgical clipping, coil embolization, or FD. The abstracts were screened by 2 authors (M.A.S. and A.P.S.), and any discrepancies were settled by discussion. Editorials, abstracts alone, reviews, case reports, articles not in English, and articles only reporting the natural history of untreated aneurysms were excluded. Studies that passed the screening stage were obtained in full text and evaluated based on our inclusion and exclusion criteria.

\section{Study Inclusion and Exclusion Criteria}

Full-text articles were included if they reported both preoperative and postoperative vision data for at least 5 patients with paraclinoid aneurysms treated with clipping, coiling, or FD. Details of the inclusion and exclusion process are outlined in Fig. 1. Studies that reported on aneurysms arising between the cavernous sinus and the origin of the posterior communicating artery were included, even if they were not described as "paraclinoid" by the article. Studies that described only the natural history of untreated aneurysms or that reported on multimodal treatment were excluded. Studies that did not separate visual outcomes by treatment modality or by aneurysm location were also excluded. If multiple series were published with the same cohort, only the largest series was included. For studies that separately reported outcomes for multiple treatment modalities, we did not require that all treatment cohorts meet our inclusion criteria; we extracted data on whichever cohorts individually met the inclusion and exclusion criteria, including the 5-patient minimum. We identified 1 additional study that met our inclusion and exclusion criteria after a backward reference search.

\section{Outcome Measures}

The primary outcome assessed in this meta-analysis was improvement in postoperative vision compared with preoperative vision in patients with paraclinoid aneurysms who presented with visual deficits. Postoperative vision was classified as improved, unchanged, or worsened compared with preoperative vision. Neuroophthalmological assessment was used when reported, but subjective patient reports or objective visual examination findings were also acceptable. Postoperative vision at the most recent follow-up was used in studies that reported visual examinations at multiple postoperative follow-up time points. We calculated the rates of improved, unchanged, and worsened vision among patients treated with clipping, coiling, or FD.

Secondary outcomes included rate of iatrogenic visual impairment, rate of presentation with visual symptoms, and rate of worsened vision after intervention. The rate of development of new visual deficits following treatment of paraclinoid aneurysms in patients who presented with intact vision was compared among clipping, coiling, and FD by using studies that met our inclusion and exclusion criteria and that also included patients who did not present with visual deficits. We also sought to assess the rate at which patients with paraclinoid aneurysms presented with visual impairment. For this calculation, we excluded studies that only reported patients who presented with visual deficits. Finally, we assessed the rate of worsened vision after treatment in patients who presented with visual symptoms.

\section{Statistical Analysis}

Rates of preoperative vision impairment, improved vision, worsened vision, and iatrogenic vision impairment were calculated using the random-effects model due to the heterogeneity among the studies. ${ }^{5}$ Because proportions are not normally distributed, we applied a FreemanTukey transformation to transform and back-transform 

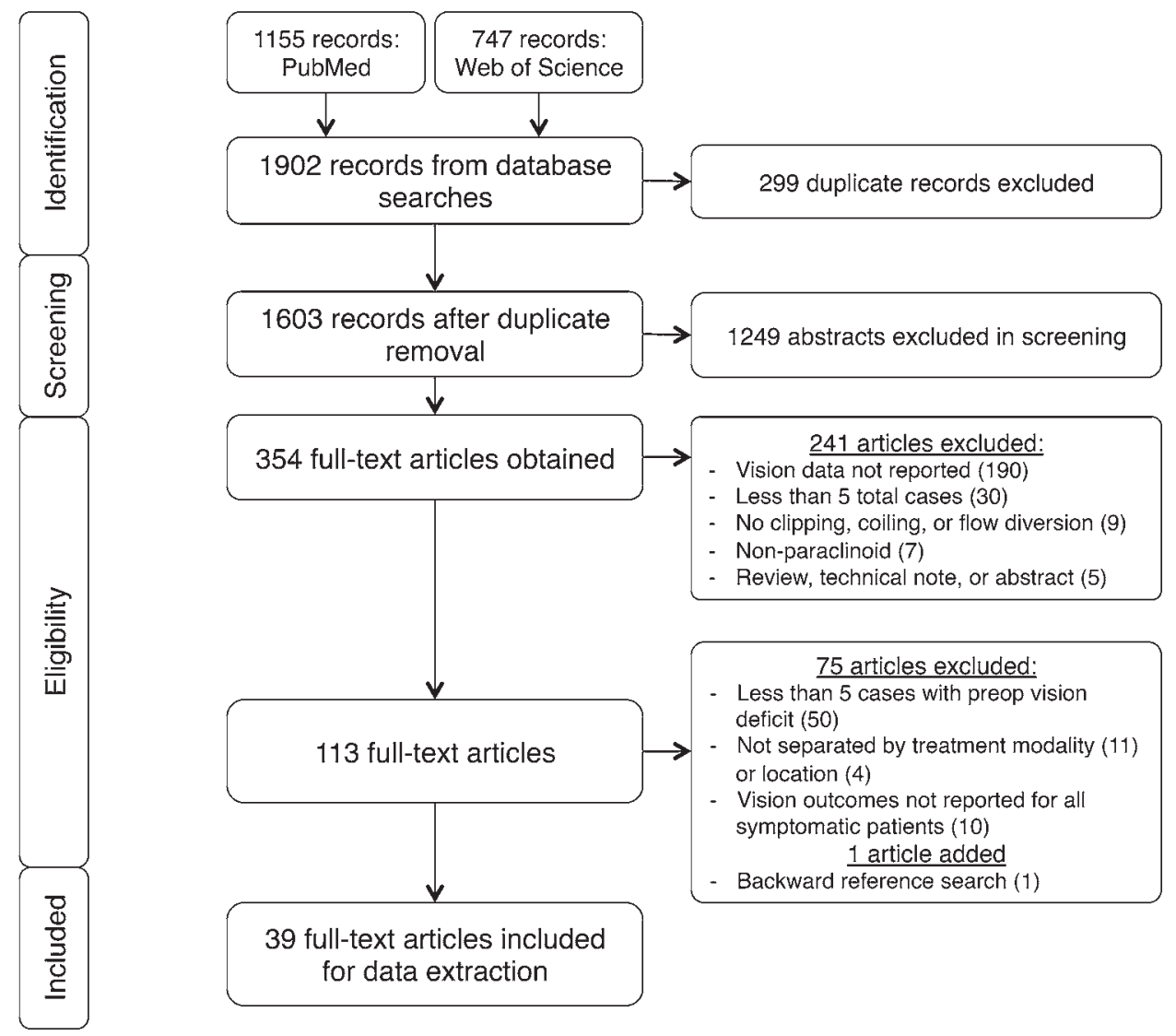

FIG. 1. Flow diagram of study inclusion and exclusion criteria during the screening and selection process.

the proportions and allow aggregation. ${ }^{35}$ The Q statistic and $\mathrm{I}^{2}$ value were used to assess heterogeneity among the clipping, coiling, and FD groups for each calculation. A forest plot was generated using the CIs calculated using the random-effects model. We also performed a univariate meta-regression between several study characteristics and vision outcomes. ${ }^{4}$ We calculated $p$ values for each of the study variables, and a cutoff of $p=0.05$ was used to test for significance. To assess the risk of publication bias, we performed a trim-and-fill analysis to generate separate funnel plots for clipping, coiling, and FD studies and analyzed the symmetry of the plots. ${ }^{16}$ Statistical analysis was completed in R (version 3.0) with methods as implemented in the metafor $\mathrm{R}$ package. Our meta-analysis and literature review protocol has not been published or registered.

\section{Results \\ Study Selection}

Results from PubMed and Web of Science database searches included a total of 1603 nonduplicate references. These records underwent a title and abstract screen that narrowed the cohort to 354 studies. These full-text articles were evaluated based on the inclusion and exclusion criteria for the study (see Methods). Thirty-nine articles were included for data extraction and analysis. A flow diagram of the screening and inclusion process is provided in Fig. 1.
Of the 39 studies included in our meta-analysis, 21 evaluated clipping, 10 evaluated coiling, 5 evaluated FD, and 3 evaluated both clipping and coiling (individually) to treat paraclinoid aneurysms.

\section{Study Characteristics}

A total of 2458 patients were treated, 520 of whom presented with visual impairment. Twenty-two (56\%) of these studies were from North America, 10 (26\%) from Asia, $5(13 \%)$ from Europe, 1 (3\%) from South America, and 1 (3\%) from Australia.

Among the clipping studies, 1363 patients were treated between 1973 and 2013. The mean follow-up was 26 months. Among the coiling studies, 738 patients were treated between 1991 and 2014. The mean follow-up was 17 months. Among the FD studies, 357 patients were treated between 2006 and 2014. The mean follow-up was 11 months. A detailed summary of the study characteristics for each of the included studies is provided in Table 1.

\section{Rate of Preoperative Visual Impairment}

A pooled analysis of all treatment modalities allowed random-effects modeling of all patients. This showed preoperative visual symptoms in $38 \%$ (95\% CI $28 \%-50 \%$ ) of patients. This excluded studies that only reported on patients who presented with visual symptoms (by definition, these studies present a cohort skewed toward 100\%). De- 
TABLE 1. Studies included in meta-analysis

\begin{tabular}{|c|c|c|c|c|c|c|c|c|c|c|}
\hline \multirow[b]{2}{*}{ Authors \& Year } & \multirow[b]{2}{*}{ Treatment } & \multirow[b]{2}{*}{ Treated } & \multirow{2}{*}{$\begin{array}{l}\text { Baseline } \\
\text { Vision } \\
\text { Impairment }\end{array}$} & \multicolumn{3}{|c|}{ Postop Vision } & \multirow{2}{*}{$\begin{array}{l}\text { Mean } \\
\text { FU } \\
\text { (mos) }\end{array}$} & \multirow{2}{*}{$\begin{array}{c}\text { New } \\
\text { Deficit }\end{array}$} & \multirow[b]{2}{*}{ Evaluation } & \multirow{2}{*}{$\begin{array}{c}\text { Country } \\
\text { (state) }\end{array}$} \\
\hline & & & & Improved & Unchanged & Worsened & & & & \\
\hline Arnautović et al., 1998 & Clip & 16 & 6 & 2 & 4 & 0 & NA & 0 & Subjective & US (AR) \\
\hline Barami et al., 2003 & Clip & 58 & 5 & 0 & 3 & 2 & 6 & 4 & Objective & US (MI) \\
\hline Date et al., 1998 & Clip & 5 & 5 & 3 & 1 & 1 & NA & 0 & Objective & Japan \\
\hline Dehdashti et al., 2012 & Clip & 257 & 12 & 9 & 2 & 1 & 24 & 2 & Ophthalmological & Canada \\
\hline Diaz et al., 1989 & Clip & 15 & 6 & 3 & 0 & 2 & NA & 0 & Subjective & US (MI) \\
\hline Durst et al., 2014 & Coil & 65 & 22 & 15 & 5 & 2 & 12 & 1 & Ophthalmological & US (VA) \\
\hline Ferguson \& Drake, 1981 & Clip & 100 & 21 & 12 & 4 & 4 & NA & NA & Objective & Canada \\
\hline Fries et al., 1997 & Clip & 51 & 19 & 15 & 1 & 3 & 72 & NA & Subjective & Germany \\
\hline Heros et al., 1983 & Clip & 23 & 16 & 10 & 2 & 4 & 6 & NA & Subjective & US (PA, MA) \\
\hline \multirow[t]{2}{*}{ Hoh et al., 2001} & Clip & 180 & 12 & 8 & 3 & 1 & NA & 4 & \multirow[t]{2}{*}{ Subjective } & \multirow[t]{2}{*}{ US (MA) } \\
\hline & Coil & 57 & 4 & 3 & 1 & 0 & 6 & 2 & & \\
\hline Kattner et al., 1998 & Clip & 29 & 10 & 5 & 4 & 1 & 84 & 0 & Subjective & US (IL) \\
\hline Lai \& Morgan, 2013 & Clip & 169 & 23 & 12 & 8 & 3 & 24.7 & 8 & Subjective & Australia \\
\hline Mattingly et al., 2013 & Clip & 18 & 14 & 11 & 0 & 3 & NA & 1 & Ophthalmological & Canada \\
\hline Meyer et al., 2001 & Clip & 36 & 13 & 2 & 10 & 1 & NA & 0 & Subjective & US (MN) \\
\hline Nanda \& Javalkar, 2011 & Clip & 80 & 15 & 10 & 3 & 0 & 27.38 & 7 & Ophthalmological & US (LA) \\
\hline Nonaka et al., 2007 & Clip & 7 & 7 & 2 & 3 & 2 & NA & NA & Subjective & Japan \\
\hline Norwood et al., 1986 & Clip & 7 & 7 & 3 & 3 & 1 & 8.57 & NA & Ophthalmological & US (AL) \\
\hline \multirow[t]{2}{*}{ Shimizu et al., 2015} & Clip & 18 & 12 & 5 & 3 & 4 & 90 & 0 & \multirow[t]{2}{*}{ Ophthalmological } & \multirow[t]{2}{*}{ Japan } \\
\hline & Coil & 21 & 6 & 4 & 1 & 1 & 90 & 1 & & \\
\hline Sun et al., 2011 & Coil & 30 & 7 & 3 & 4 & 0 & 12.8 & 0 & NA & China \\
\hline Szikora et al., 2013 & $\begin{array}{l}\text { FD (PED, } \\
\text { Silk) }\end{array}$ & 81 & 6 & 5 & 0 & 1 & 6 & 2 & NA & Hungary \\
\hline Tanweer et al., 2014 & FD (PED) & 41 & 19 & 16 & 3 & 0 & 24.6 & 0 & Ophthalmological & US (NY) \\
\hline Wang et al., $2013^{53}$ & Coil & 136 & 13 & 4 & 9 & 0 & 16.6 & 0 & Ophthalmological & China \\
\hline Wang et al., $2013^{54}$ & Coil & 56 & 7 & 3 & 4 & 0 & 18.45 & 0 & Subjective & China \\
\hline Xu et al., 2008 & Clip & 36 & 15 & 8 & 4 & 3 & NA & 0 & NA & China \\
\hline Xu et al., 2010 & Clip & 51 & 17 & 12 & 3 & 2 & 6 & 0 & NA & China \\
\hline Yadla et al., 2011 & Coil & 147 & 13 & 4 & 4 & 0 & 20 & 0 & Ophthalmological & US (PA) \\
\hline Zanaty et al., 2015 & FD (PED) & 41 & 12 & 9 & 3 & 0 & 9.86 & 0 & Ophthalmological & US (PA) \\
\hline Zhao et al., 2006 & Clip & 60 & 25 & 21 & 4 & 0 & 3 & 2 & NA & China \\
\hline
\end{tabular}

$\mathrm{FU}=$ follow-up; NA = not available from study report.

All values are reported as the number of patients unless otherwise indicated. 


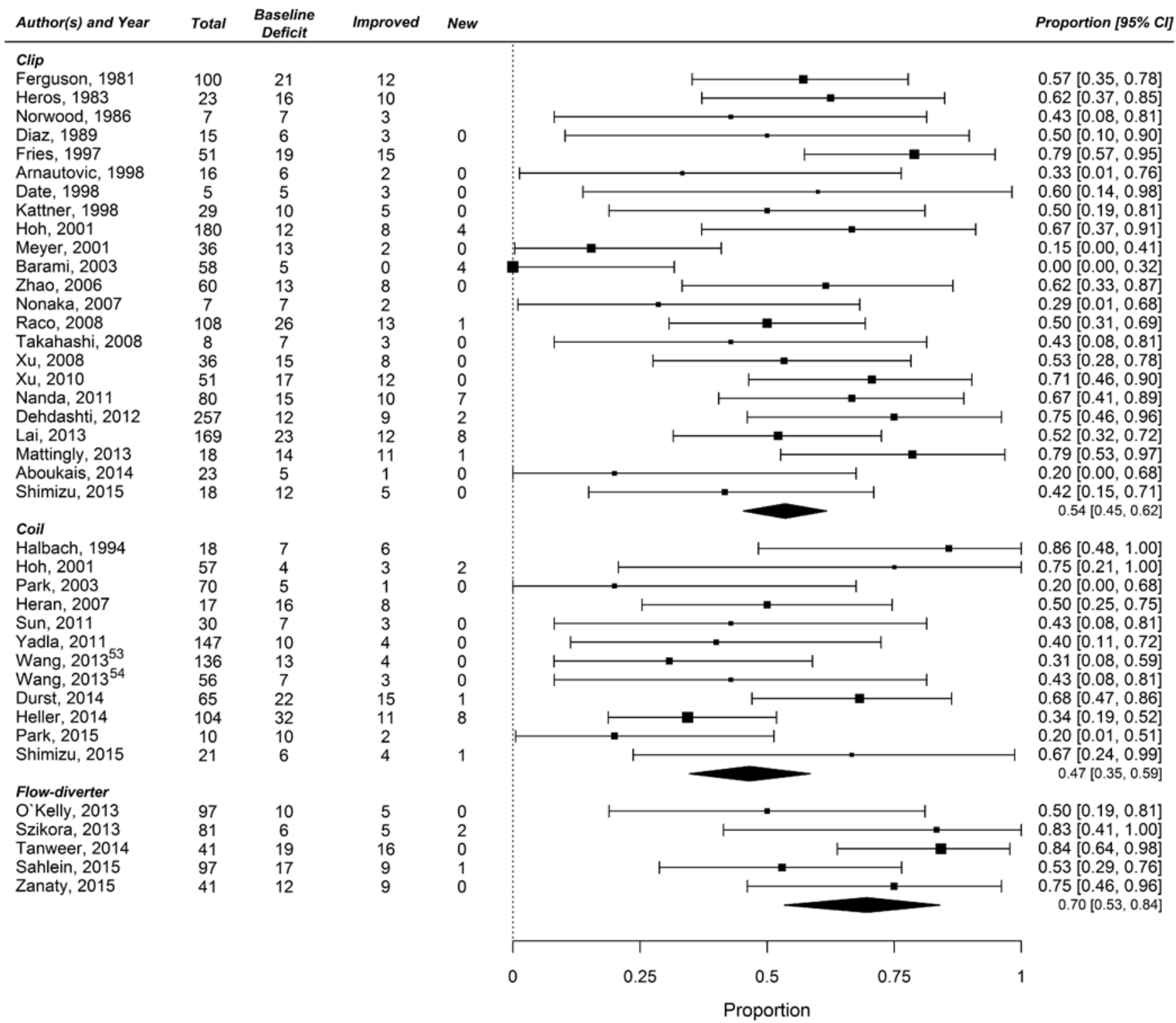

FIG. 2. Forest plot of the rate of vision improvement based on the random-effects model for studies using clipping, coiling, or FD. Values are reported as the number of patients unless otherwise indicated.

spite this exclusion, there was heterogeneity in the study reports: $\mathrm{Q}=553.71 ; \mathrm{p}<0.0001 ; \mathrm{I}^{2}=96 \%$.

\section{Changes in Vision Deficit}

Fifty-eight percent (95\% CI 48\%-68\%) of patients had improved vision after clipping of paraclinoid aneurysms. A $\mathrm{Q}$ statistic of $57.48(\mathrm{p}<0.0001)$ and an $\mathrm{I}^{2}$ value of $61.18 \%$ suggested a heterogeneous mix of reported results (as appreciated in the forest plot), with some groups reporting no improvement whereas others reported universal improvement (Fig. 2). The rate of worsened vision after clipping was $11 \%$ (95\% CI 7\%-17\%), with no evidence of heterogeneity $\left(\mathrm{Q}=30.37 ; \mathrm{p}=0.1391 ; \mathrm{I}^{2}=26 \%\right)$.

The calculated rate of visual improvement for paraclinoid aneurysms treated with coiling was $49 \%$ (95\% CI $38 \%-59 \%$ ), with homogenous results among the studies
$\left(\mathrm{Q}=15.04 ; \mathrm{p}=0.2 ; \mathrm{I}^{2}=23.29 \%\right)$. The rate of worsened vision after coiling was $9 \%$ (95\% CI 2\%-18\%). These findings demonstrated borderline heterogeneity $(\mathrm{Q}=19.62 ; \mathrm{p}$ $=0.07 ; \mathrm{I}^{2}=41 \%$ ).

FD improved vision in 71\% (95\% CI 55\%-84\%) of patients. These studies reported homogeneous treatment effects $\left(\mathrm{Q}=5.19 ; \mathrm{p}=0.2 ; \mathrm{I}^{2}=29 \%\right)$. Five percent $(95 \% \mathrm{CI}$ $0 \%-20 \%$ ) of patients had worsened vision after FD, but the studies reported heterogeneous results $(\mathrm{Q}=11.20 ; \mathrm{p}=$ $0.02 ; \mathrm{I}^{2}=62 \%$ ). A forest plot for the rate of vision improvement based on the random-effects model for each of the 3 modalities is shown in Fig. 2.

\section{Rate of latrogenic Visual Impairment}

New visual deficits occurred after clipping in 1\% (95\% CI $0 \%-3 \%$ ) of patients, after coiling in $0 \%$ (95\% CI $0 \%-$ 

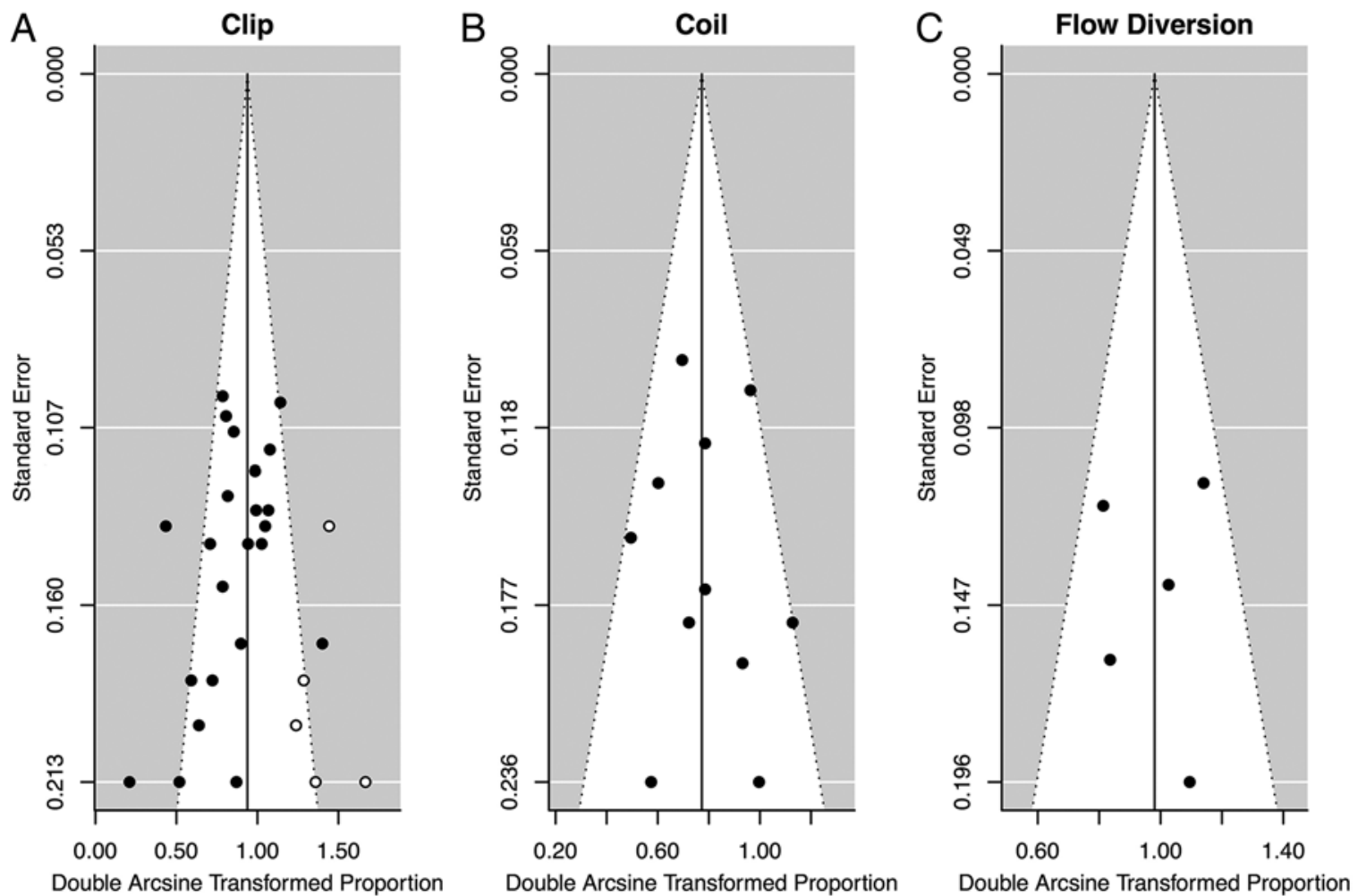

FIG. 3. Funnel plots evaluating the likelihood of publication bias. Clipping studies $(\mathbf{A})$ may have had possible underreporting of patients with improved vision, as shown in the moderately right-skewed plot. Coiling studies (B) and FD studies (C) produced symmetric funnel plots, with no evidence of publication bias.

$2 \%)$ of patients, and after FD in $0 \%(95 \%$ CI $0 \%-2 \%)$ of patients. There was heterogeneity in the studies of clipping $\left(\mathrm{Q}=25.85 ; \mathrm{p}=0.04 ; \mathrm{I}^{2}=44 \%\right)$ and coiling $(\mathrm{Q}=27.19 ; \mathrm{p}$ $\left.=0.0007 ; \mathrm{I}^{2}=69 \%\right)$, but not for FD $\left(\mathrm{Q}=2.86 ; \mathrm{p}=0.6 ; \mathrm{I}^{2}\right.$ $=1.32 \%$ ).

\section{Results of Meta-Regression}

Univariate meta-regression assessing the relationship between either publication year, first and last year of the study, or mean follow-up and either the rate of preoperative visual symptoms, rate of visual improvement, rate of worsened vision, or rate of iatrogenic vision impairment showed no associations with any of the outcomes, both when the treatment modalities were regressed in isolation or when all patients were pooled for the analysis.

\section{Likelihood of Publication Bias}

Funnel plots for each of the 3 treatment modalities demonstrated no evidence of publication bias for the coiling or FD studies, which yielded symmetric funnel plots (Fig. 3B and 3C). However, the clipping studies demonstrated the possibility of underreporting patients with greater improvement of vision, as evidenced by moderate asymmetry and a right skew in the funnel plot (Fig. 3A).

\section{Discussion}

Due to the high rate of visual impairment among pa- tients with paraclinoid aneurysms, it is important to compare postoperative visual outcomes among clipping, coiling, and FD when choosing which treatment modality to use, among other factors. It is unclear which one is the optimal treatment for patients with visually symptomatic paraclinoid aneurysms based on the current literature. Existing studies comparing these treatment modalities have focused on general outcomes, but did not consider vision.

Prior to the introduction of FD, treatment of paraclinoid aneurysms was limited to clipping or coiling. Studies comparing general outcomes between clipping and coiling, when considered collectively, are inconclusive. The International Subarachnoid Aneurysm Trial, which broadly included unruptured aneurysms and did not focus on paraclinoid aneurysms, randomly assigned 2143 patients to either clipping or coiling between 1994 and 2002. ${ }^{36}$ Coiling demonstrated a higher rate of rebleeding, but a lower mortality rate and a higher rate of disability-free survival at 10 years. ${ }^{8,37,38}$ Brinjikji et al. performed an analysis of 29,918 cases of clipping and 34,125 cases of coiling between 2001 and 2008 in the United States using the National Inpatient Sample. They found a higher mortality rate $(1.2 \%$ vs $0.6 \%)$ and a higher rate of discharge to a long-term care facility (14.0\% vs $4.9 \%$ ) for clipping compared with coiling. ${ }^{6}$

McDonald et al. compared outcomes for 4899 patients treated with clipping or coiling between 2006 and 2011 at 120 US hospitals. They found comparable mortality rates between the groups, but a higher rate of periprocedural 
morbidity and a higher rate of discharge to long-term care for clipping compared with coiling. ${ }^{33}$ Although these studies did not focus on paraclinoid aneurysms, they provide a large volume of the existing data comparing general outcomes among clipping, coiling, and FD. They remain inconclusive on the broad outcomes of morbidity, mortality, and disability. In the decision making for paraclinoid aneurysms, vision outcomes should be considered among the many variables used to decide on treatment.

No existing study, to the best of our knowledge, has specifically compared the use of clipping, coiling, and FD for patients with paraclinoid aneurysms who present with visual symptoms. Mechanistic explanations have been proposed for potential differences in vision outcomes. Clipping may facilitate preservation of the ophthalmic artery for paraclinoid aneurysms arising near its takeoff; clipping is thought to also provide a greater reduction in mass effect and a more robust decompression of the optic nerve compared with coiling..$^{1,12,39,47}$ Coiling, on the other hand, fills the aneurysm sac and perpetuates its mass effect, perhaps even inducing swelling and worsening optic nerve compression..$^{39}$

The PED and other flow diverters promote thrombosis of the aneurysm while permitting blood flow to perforators incidentally covered by the stent. ${ }^{19}$ Of particular relevance to vision outcomes and optic nerve compression, FD promotes reabsorption of the thrombus and theoretically diminishes mass effect. ${ }^{19,51}$ However, few studies have comprehensively compared FD with clipping and coiling, and none have specifically compared vision outcomes. Zhu et al. performed a pooled analysis comparing clipping, coiling, and FD for treatment of paraclinoid aneurysms. Their analysis of 33 studies with a total of 1473 patients showed no significant differences in mortality or poor outcome among the treatment groups; however, their data on patient vision were limited to reporting visual complications rather than improvement from baseline. ${ }^{60}$

The primary outcome of our study was the rate of vision improvement. We found that $58 \%$ of patients treated with clipping, $49 \%$ of patients treated with coiling, and $71 \%$ of patients treated with FD had improved postoperative vision. The differences in these rates of visual improvement were not found to be statistically significant, and significant heterogeneity was observed in the clipping group. No significant differences in the rate of visual worsening were found among the 3 groups either, despite heterogeneity in the coiling and FD groups. Altogether, these findings are inconclusive but provide promising evidence that FD may yield higher rates of visual improvement compared with clipping and coiling, with no difference in the rate of worsened vision. More data are needed to achieve more conclusive findings.

This meta-analysis also sought to assess the rate at which patients with paraclinoid aneurysms presented with visual impairment. Existing reports of the rate of visual symptoms in patients with paraclinoid aneurysms vary. One of the earliest multiyear series of visually symptomatic paraclinoid aneurysms by Day found that $36 \%$ of the 41 aneurysms treated caused visual symptoms. ${ }^{11}$ Lai and Morgan found that $16.6 \%$ of their 169 patients with unruptured paraclinoid aneurysms presented with visual symptoms. ${ }^{31}$ Most recently, Sahlein et al. performed a secondary analysis of the Pipeline for Uncoilable or Failed Aneurysms trial and found that $40 \%$ of 98 patients with paraclinoid aneurysms had preoperative visual impairment; however, this analysis only considered large and giant aneurysms. ${ }^{46}$ The heterogeneity of the data reported in the literature demonstrates that there is no conclusive estimate for the rate of visual symptoms among patients with paraclinoid aneurysms. This meta-analysis of 39 studies with a total of 2458 patients found that $38 \%$ of patients with paraclinoid aneurysms presented with visual impairment across a range of aneurysm sizes, geographic regions, and referral patterns.

Visual deficits are also a known complication of paraclinoid aneurysms: retinal artery thrombosis during coiling or FD, and retraction injury or thermal injury during clinoidectomy have been described..$^{9,39}$ Visual impairment after surgical clipping is thought to result from manipulation of the optic nerve, which must be mobilized to access the neck of the aneurysm. ${ }^{30}$ Some cases of iatrogenic visual impairment after PED treatment have also been reported. ${ }^{46,51}$ Burrows et al. recently reported a series of 44 patients with paraclinoid aneurysms treated with FD, none of whom experienced permanent vision loss after treatment. ${ }^{7}$ Griessenauer et al. also found low rates of visual impairment after PED treatment of paraophthalmic aneurysms in a series of 52 patients..$^{21}$ To our knowledge, our meta-analysis is the first comprehensive comparison of the rates of visual complications among clipping, coiling, and FD. The overall rates of visual complications in our study were low, and there were no significant differences between the treatment modalities despite heterogeneity in the clipping and coiling groups.

There are several limitations of this meta-analysis. First, the trim-and-fill analysis and funnel plots demonstrate evidence of underreporting bias among the clipping studies, but not for coiling or FD. The asymmetry and right skew of the funnel plot suggest that the clipping studies included in the meta-analysis underreported patients with a greater proportion of improvement. Second, as previously discussed, there was evidence of heterogeneity in the reporting of vision outcomes for several of our analyses.

Third, there are limitations at the level of the interventions described in this study. Some of the studies in the coiling group used stent-assisted techniques for a subset of their treatment population, but did not separately report vision outcomes. Although these stents did not have flow-diverting characteristics, stent-assisted coiling is associated with an increased thromboembolic complication risk. We included these studies and placed all patients in the coiling group, which may have confounded the complication rate. Similarly, the FD group included studies that used PED, Silk, or a mix of these 2 flow-diverting stents. Thus, conclusions drawn from the study cannot be specifically tied to 1 device or the other.

Fourth, the quality of evaluation and reporting of visual deficits and vision changes varied among the included studies. Some studies reported both preoperative and postoperative neuroophthalmological examinations for all patients, whereas others only included subjective reports of visual symptoms, and still others reported a mix. The reli- 
ability of neuroophthalmological examination is presumed to be superior to that of subjective patient reporting, and neuroophthalmological findings were used when available. Studies that relied more on subjective findings may not have been as reliable. Altogether, more than half of included studies reported objective visual findings, including $38 \%$ that reported formal ophthalmological examinations.

Fifth, our calculation of the rate of iatrogenic vision impairment following treatment may have been subject to selection bias. This is because only studies that met our inclusion and exclusion criteria for patients with preoperative visual impairment were included in the calculation. Because iatrogenic vision impairment was a secondary outcome in this meta-analysis, the inclusion criteria were designed with our primary outcome of vision improvement in mind. Therefore, we excluded many studies that reported on patients who developed iatrogenic vision impairment but that did not meet our criteria for the minimum number of patients presenting with visual symptoms. Importantly, we defined iatrogenic vision impairment as a new visual deficit that developed in a patient who presented with intact vision. Therefore, patients who developed an iatrogenic decline in vision after presenting with visual impairment were included in the "worsened" category and were excluded from the iatrogenic calculation. We sought to highlight true iatrogenic vision impairment and to exclude false-positive results (that is, progression of a preoperative visual impairment unrelated to treatment) by isolating visual deficits that developed in patients who presented with intact vision.

Last, our analysis of FD was limited by the novelty of this treatment modality. It has been approved for use in the United States only within the past decade and has only recently been applied to paraclinoid aneurysms. Thus, far fewer studies were included in the FD group compared with the clipping and coiling groups. Only 5 studies using FD, with a total of 357 patients and spanning 8 years, met our inclusion criteria. Additionally, the mean follow-up for the FD studies was shorter: 11 months compared with 26 months for clipping and 17 months for coiling. The smaller sample size and the shorter mean follow-up may have confounded our findings. However, longer follow-up is typically associated with a higher proportion of improved vision. Therefore, longer follow-up may have strengthened our finding of higher rates of visual improvement for FD.

\section{Conclusions}

To our knowledge, this is the first meta-analysis to compare vision outcomes for paraclinoid aneurysms treated with clipping, coiling, or FD. We found that $38 \%$ of patients with paraclinoid aneurysms presented with visual impairment. Although not statistically significant, our study suggests that FD may be associated with higher rates of visual improvement and that it is not associated with any difference in the rates of worsened vision or iatrogenic visual impairment compared with clipping and coiling. Considering the limited data available for FD, the promising and broadly generalizable findings of this study suggest that FD is an effective option for the treatment of visually symptomatic paraclinoid aneurysms.

\section{Appendix}

(“Aneurysm”[MeSH] OR “aneurysm”[tiab] OR "Subarachnoid Hemorrhage"[MeSH] OR "subarachnoid hemorrhage"[tiab])

AND

("Ophthalmic Artery”[MeSH] OR "ophthalmic"[tiab] OR “paraclinoid"[tiab] OR "clinoidal"[tiab] OR "superior hypophyseal"[tiab] OR “cavernous"[tiab] OR "Vision, Ocular" $[\mathrm{MeSH}]$ OR "Vision, Low"[MeSH] OR "vision" [tiab] OR "Hemianopsia"[MeSH] OR "hemianopsia" [tiab] OR "quadrantanopsia"[tiab] OR "quandrantanopia”[tiab] OR "Amaurosis Fugax"[MeSH] OR "amaurosis"[tiab] OR "Ischemic Attack, Transient”[MeSH] OR "transient ischemic attack”[tiab] OR “tia”"[tiab])

AND

("clipping"[tiab] OR "coiling"[tiab] OR "flow diversion" [tiab] OR "pipeline"[tiab] OR "endovascular"'[tiab] OR "embolization"[tiab] OR "flow diverter"[tiab] OR "Stents" [MeSH] OR "stent"[tiab] OR “stents"[tiab] OR "microsurgical”[tiab] OR "clip reconstruction"[tiab] OR "packing"[tiab] OR "Raymond Score" [tiab] OR "Raymond - Roy Occlusion classification”[tiab]).

\section{References}

1. Aboukaïs R, Zairi F, Bourgeois P, Thines L, Kalsoum E, Leclerc X, et al: Clinical and imaging follow-up after surgical or endovascular treatment in patients with unruptured carotid-ophthalmic aneurysm. Clin Neurol Neurosurg 125:155-159, 2014

2. Arnautović KI, Al-Mefty O, Angtuaco E: A combined microsurgical skull-base and endovascular approach to giant and large paraclinoid aneurysms. Surg Neurol 50:504-520, 1998

3. Barami K, Hernandez VS, Diaz FG, Guthikonda M: Paraclinoid carotid aneurysms: surgical management, complications, and outcome based on a new classification scheme. Skull Base 13:31-41, 2003

4. Berkey CS, Hoaglin DC, Antczak-Bouckoms A, Mosteller F, Colditz GA: Meta-analysis of multiple outcomes by regression with random effects. Stat Med 17:2537-2550, 1998

5. Berkey CS, Hoaglin DC, Mosteller F, Colditz GA: A random-effects regression model for meta-analysis. Stat Med 14:395-411, 1995

6. Brinjikji W, Rabinstein AA, Nasr DM, Lanzino G, Kallmes DF, Cloft HJ: Better outcomes with treatment by coiling relative to clipping of unruptured intracranial aneurysms in the United States, 2001-2008. AJNR Am J Neuroradiol 32:1071-1075, 2011

7. Burrows AM, Brinjikji W, Puffer RC, Cloft H, Kallmes DF, Lanzino G: Flow diversion for ophthalmic artery aneurysms. AJNR Am J Neuroradiol [epub ahead of print], 2016

8. Campi A, Ramzi N, Molyneux AJ, Summers PE, Kerr RS, Sneade M, et al: Retreatment of ruptured cerebral aneurysms in patients randomized by coiling or clipping in the International Subarachnoid Aneurysm Trial (ISAT). Stroke 38:1538-1544, 2007

9. Castillo B Jr, De Alba F, Thornton J, DeBrun G, Pulido J: Retinal artery occlusion following coil embolization of carotid-ophthalmic aneurysms. Arch Ophthalmol 118:851-852, 2000

10. Date I, Asari S, Ohmoto T: Cerebral aneurysms causing visual symptoms: their features and surgical outcome. Clin Neurol Neurosurg 100:259-267, 1998

11. Day AL: Aneurysms of the ophthalmic segment. A clinical and anatomical analysis. J Neurosurg 72:677-691, 1990

12. de Oliveira JG, Borba LA, Rassi-Neto A, de Moura SM, Sanchez-Júnior SL, Rassi MS, et al: Intracranial aneurysms presenting with mass effect over the anterior optic pathways: neurosurgical management and outcomes. Neurosurg Focus 26(5):E3, 2009

13. Dehdashti AR, Le Roux A, Bacigaluppi S, Wallace MC: Long-term visual outcome and aneurysm obliteration rate 
for very large and giant ophthalmic segment aneurysms: assessment of surgical treatment. Acta Neurochir (Wien) 154:43-52, 2012

14. Diaz FG, Ohaegbulam S, Dujovny M, Ausman JI: Surgical alternatives in the treatment of cavernous sinus aneurysms. J Neurosurg 71:846-853, 1989

15. Durst CR, Starke RM, Gaughen J, Nguyen Q, Patrie J, Jensen $\mathrm{ME}$, et al: Vision outcomes and major complications after endovascular coil embolization of ophthalmic segment aneurysms. AJNR Am J Neuroradiol 35:2140-2145, 2014

16. Duval S, Tweedie R: Trim and fill: A simple funnel-plotbased method of testing and adjusting for publication bias in meta-analysis. Biometrics 56:455-463, 2000

17. Ferguson GG, Drake CG: Carotid-ophthalmic aneurysms: visual abnormalities in 32 patients and the results of treatment. Surg Neurol 16:1-8, 1981

18. Ferrell AS, Lessne ML, Alexander MJ, Shah P, Golshani K, Zomorodi A, et al: Visual complications after stent-assisted endovascular embolization of paraophthalmic and suprasellar variant superior hypophyseal aneurysms: the Duke Cerebrovascular Center experience in 57 patients. World Neurosurg 78:289-294, 2012

19. Fiorella D, Lylyk P, Szikora I, Kelly ME, Albuquerque FC, McDougall CG, et al: Curative cerebrovascular reconstruction with the Pipeline embolization device: the emergence of definitive endovascular therapy for intracranial aneurysms. J Neurointerv Surg 1:56-65, 2009

20. Fries G, Perneczky A, van Lindert E, Bahadori-Mortasawi F: Contralateral and ipsilateral microsurgical approaches to carotid-ophthalmic aneurysms. Neurosurgery 41:333-343, 1997

21. Griessenauer CJ, Ogilvy CS, Foreman PM, Chua MH, Harrigan MR, Stapleton CJ, et al: Pipeline Embolization Device for small paraophthalmic artery aneurysms with an emphasis on the anatomical relationship of ophthalmic artery origin and aneurysm. J Neurosurg 125:1352-1359, 2016

22. Halbach VV, Higashida RT, Dowd CF, Barnwell SL, Fraser KW, Smith TP, et al: The efficacy of endosaccular aneurysm occlusion in alleviating neurological deficits produced by mass effect. J Neurosurg 80:659-666, 1994

23. Heller RS, Lawlor CM, Hedges TR III, Bababekov YJ, Safain MG, Malek AM: Neuro-ophthalmic effects of stenting across the ophthalmic artery origin in the treatment of intracranial aneurysms. J Neurosurg 121:18-23, 2014

24. Heran NS, Song JK, Kupersmith MJ, Niimi Y, Namba K, Langer DJ, et al: Large ophthalmic segment aneurysms with anterior optic pathway compression: assessment of anatomical and visual outcomes after endosaccular coil therapy. $\mathbf{J}$ Neurosurg 106:968-975, 2007

25. Heros RC, Nelson PB, Ojemann RG, Crowell RM, DeBrun G: Large and giant paraclinoid aneurysms: surgical techniques, complications, and results. Neurosurgery 12:153163,1983

26. Hoh BL, Carter BS, Budzik RF, Putman CM, Ogilvy CS: Results after surgical and endovascular treatment of paraclinoid aneurysms by a combined neurovascular team. Neurosurgery 48:78-90, 2001

27. Kallmes DF, Ding YH, Dai D, Kadirvel R, Lewis DA, Cloft HJ: A new endoluminal, flow-disrupting device for treatment of saccular aneurysms. Stroke 38:2346-2352, 2007

28. Kanagalingam S, Gailloud P, Tamargo RJ, Subramanian PS, Miller NR: Visual sequelae after consensus-based treatment of ophthalmic artery segment aneurysms: the Johns Hopkins experience. J Neuroophthalmol 32:27-32, 2012

29. Kattner KA, Bailes J, Fukushima T: Direct surgical management of large bulbous and giant aneurysms involving the paraclinoid segment of the internal carotid artery: report of 29 cases. Surg Neurol 49:471-480, 1998

30. Kobayashi S, Kyoshima K, Gibo H, Hegde SA, Takemae T,
Sugita K: Carotid cave aneurysms of the internal carotid artery. J Neurosurg 70:216-221, 1989

31. Lai LT, Morgan MK: Outcomes for unruptured ophthalmic segment aneurysm surgery. J Clin Neurosci 20:1127-1133, 2013

32. Mattingly T, Kole MK, Nicolle D, Boulton M, Pelz D, Lownie SP: Visual outcomes for surgical treatment of large and giant carotid ophthalmic segment aneurysms: a case series utilizing retrograde suction decompression (the "Dallas technique"). J Neurosurg 118:937-946, 2013

33. McDonald JS, McDonald RJ, Fan J, Kallmes DF, Lanzino G, Cloft HJ: Comparative effectiveness of unruptured cerebral aneurysm therapies: propensity score analysis of clipping versus coiling. Stroke 44:988-994, 2013

34. Meyer FB, Friedman JA, Nichols DA, Windschitl WL: Surgical repair of clinoidal segment carotid artery aneurysms unsuitable for endovascular treatment. Neurosurgery 48:476-486, 2001

35. Miller JJ: Inverse of Freeman-Tukey double arcsine transformation. Am Stat 32:138, 1978

36. Molyneux A, Kerr R, Stratton I, Sandercock P, Clarke M, Shrimpton J, et al: International Subarachnoid Aneurysm Trial (ISAT) of neurosurgical clipping versus endovascular coiling in 2143 patients with ruptured intracranial aneurysms: a randomized trial. J Stroke Cerebrovasc Dis 11:304-314, 2002

37. Molyneux AJ, Birks J, Clarke A, Sneade M, Kerr RS: The durability of endovascular coiling versus neurosurgical clipping of ruptured cerebral aneurysms: 18 year follow-up of the UK cohort of the International Subarachnoid Aneurysm Trial (ISAT). Lancet 385:691-697, 2015

38. Molyneux AJ, Kerr RS, Yu LM, Clarke M, Sneade M, Yarnold JA, et al: International Subarachnoid Aneurysm Trial (ISAT) of neurosurgical clipping versus endovascular coiling in 2143 patients with ruptured intracranial aneurysms: a randomised comparison of effects on survival, dependency, seizures, rebleeding, subgroups, and aneurysm occlusion. Lancet 366:809-817, 2005

39. Nanda A, Javalkar V: Microneurosurgical management of ophthalmic segment of the internal carotid artery aneurysms: single-surgeon operative experience from Louisiana State University, Shreveport. Neurosurgery 68:355-371, 2011

40. Nonaka T, Haraguchi K, Baba T, Koyanagi I, Houkin K: Clinical manifestations and surgical results for paraclinoid cerebral aneurysms presenting with visual symptoms. Surg Neurol 67:612-619, 2007

41. Norwood EG, Kline LB, Chandra-Sekar B, Harsh GR III: Aneurysmal compression of the anterior visual pathways. Neurology 36:1035-1041, 1986

42. O'Kelly CJ, Spears J, Chow M, Wong J, Boulton M, Weill A, et al: Canadian experience with the Pipeline Embolization Device for repair of unruptured intracranial aneurysms. AJNR Am J Neuroradiol 34:381-387, 2013

43. Park HK, Horowitz M, Jungreis C, Kassam A, Koebbe C, Genevro J, et al: Endovascular treatment of paraclinoid aneurysms: experience with 73 patients. Neurosurgery 53:14-24, 2003

44. Park W, Park JC, Han K, Ahn JS, Kwun BD: Anterior optic pathway compression due to internal carotid artery aneurysms: neurosurgical management and outcomes. J Stroke 17:344-353, 2015

45. Raco A, Frati A, Santoro A, Vangelista T, Salvati M, Delfini $\mathrm{R}$, et al: Long-term surgical results with aneurysms involving the ophthalmic segment of the carotid artery. J Neurosurg 108:1200-1210, 2008

46. Sahlein DH, Fouladvand M, Becske T, Saatci I, McDougall CG, Szikora I, et al: Neuroophthalmological outcomes associated with use of the Pipeline Embolization Device: analysis of the PUFS trial results. J Neurosurg 123:897-905, 2015 
47. Schuss P, Güresir E, Berkefeld J, Seifert V, Vatter H: Influence of surgical or endovascular treatment on visual symptoms caused by intracranial aneurysms: single-center series and systematic review. J Neurosurg 115:694-699, 2011

48. Shimizu T, Naito I, Aihara M, Fujimaki H, Asakura K, Miyamoto N, et al: Visual outcomes of endovascular and microsurgical treatment for large or giant paraclinoid aneurysms. Acta Neurochir (Wien) 157:13-20, 2015

49. Subramanian PS, Miller NR, Renard V, Tamargo RJ: Delayed progressive visual loss following wrapping of bilateral clinoidal aneurysms: recovery of vision and improvement in neuroimaging during corticosteroid treatment. Br J Ophthalmol 89:1666-1668, 2005

50. Sun Y, Li Y, Li AM: Endovascular treatment of paraclinoid aneurysms. Interv Neuroradiol 17:425-430, 2011

51. Szikora I, Marosfoi M, Salomváry B, Berentei Z, Gubucz I: Resolution of mass effect and compression symptoms following endoluminal flow diversion for the treatment of intracranial aneurysms. AJNR Am J Neuroradiol 34:935-939, 2013

52. Tanweer O, Raz E, Brunswick A, Zumofen D, Shapiro M, Riina HA, et al: Cavernous carotid aneurysms in the era of flow diversion: a need to revisit treatment paradigms. AJNR Am J Neuroradiol 35:2334-2340, 2014

53. Wang Y, Li Y, Jiang C, Jiang F, Meng H, Siddiqui AH, et al: Endovascular treatment of paraclinoid aneurysms: 142 aneurysms in one centre. J Neurointerv Surg 5:552-556, 2013

54. Wang Y, Li Y, Jiang C, Wu Z, Jiang F, Meng H, et al: Could the types of paraclinoid aneurysm be used as a criterion in choosing endovascular treatment? Neuro-radiologists' view. Acta Neurochir (Wien) 155:2019-2027, 2013

55. Xu BN, Sun ZH, Jiang JL, Wu C, Zhou DB, Yu XG, et al: Surgical management of large and giant intracavernous and paraclinoid aneurysms. Chin Med J (Engl) 121:1061-1064, 2008

56. Xu BN, Sun ZH, Romani R, Jiang JL, Wu C, Zhou DB, et al: Microsurgical management of large and giant paraclinoid aneurysms. World Neurosurg 73:137-146, e17, e19, 2010
57. Yadla S, Campbell PG, Grobelny B, Jallo J, Gonzalez LF, Rosenwasser RH, et al: Open and endovascular treatment of unruptured carotid-ophthalmic aneurysms: clinical and radiographic outcomes. Neurosurgery 68:1434-1443, 2011

58. Zanaty M, Chalouhi N, Barros G, Schwartz EW, Saigh MP, Starke RM, et al: Flow-diversion for ophthalmic segment aneurysms. Neurosurgery 76:286-290, 2015

59. Zhao J, Wang S, Zhao Y, Sui D, Zhang Y, Tang J, et al: Microneurosurgical management of carotid-ophthalmic aneurysms. J Clin Neurosci 13:330-333, 2006

60. Zhu Y, Pan J, Shen J, Liu C, Fan Z, Shen Y, et al: Clinical and radiological outcomes after treatment of unruptured paraophthalmic internal carotid artery aneurysms: a comparative and pooled analysis of single-center experiences. World Neurosurg 84:1726-1738, 2015

\section{Disclosures}

Dr. Aziz-Sultan is a proctor for Medtronic and participates in the training of other physicians in use of the PED. He is also a consultant for Covidien.

\section{Author Contributions}

Conception and design: all authors. Acquisition of data: See, Silva, Dasenbrock. Analysis and interpretation of data: See, Silva. Drafting the article: See, Silva. Critically revising the article: See, Silva, Patel, Aziz-Sultan. Reviewed submitted version of manuscript: all authors. Approved the final version of the manuscript on behalf of all authors: See. Statistical analysis: See, Silva. Administrative/technical/material support: Aziz-Sultan. Study supervision: Patel, Aziz-Sultan.

\section{Correspondence}

Alfred P. See, Department of Neurosurgery, Brigham and Women's Hospital, Harvard Medical School, 75 Francis St., Boston, MA 02115.email: psee@partners.org. 